\title{
Reproductive management practices on dairy farms: The Canadian National Dairy Study 2015
}

\author{
Sabrina J. Van Schyndel, ${ }^{1 *}$ Cathy A. Bauman, ${ }^{1}$ Osvaldo Bogado Pascottini, ${ }^{1}$ David L. Renaud, ${ }^{1}$ \\ Jocelyn Dubuc, ${ }^{2}$ and David F. Kelton ${ }^{1}$ \\ ${ }^{1}$ Department of Population Medicine, University of Guelph, Guelph, Ontario, Canada, N1G 2W1 \\ ${ }^{2}$ Faculty of Veterinary Medicine, Université de Montréal, Saint-Hyacinthe, Québec, Canada, J2S 7C6
}

\section{ABSTRACT}

The objectives of this cross-sectional study were to characterize reproductive management practices on Canadian dairy farms and describe differences based on regional and demographic factors. A questionnaire was offered to all licensed Canadian dairy producers and included 189 questions regarding producer and farm background information, herd dynamics, biosecurity, disease prevalence, calf health, animal welfare, milking practices, reproduction, and internet use. Twenty-four questions were related to estrus detection, hormonal protocols for reproduction, insemination, and pregnancy diagnosis. A total of 1,373 producers responded to the survey, representing a response rate of $12.5 \%$. Estrus detection practices in lactating cows were associated with herd size, barn type, region, organic production, breeding method, and age of respondent. The most commonly used estrus-detection method in cows was visual $(51.0 \%$ of farms for first insemination; $45.5 \%$ for subsequent inseminations). Estrus detection for nulliparous heifers was associated with herd size, barn type, region, and breeding method, with visual detection also the most common method for heifers (71.3\% of farms). Eighty percent of farms used strictly artificial insemination, $2.8 \%$ used natural service only, and $16.8 \%$ used a combination of artificial insemination and natural service. Breeding method was associated with herd size, barn type, region, and education level of the respondent. Pregnancy diagnosis method was associated with herd size, barn type, region, and organic production. Ultrasound was the most commonly used method of pregnancy diagnosis (used by $52.2 \%$ of farms). Sixty-nine percent of farms rechecked cows for pregnancy, and rectal palpation was the most com-

Received March 3, 2018.

Accepted October 26, 2018

*Corresponding author: vanschys@uoguelph.ca monly used method (employed by $48.7 \%$ ). Reproductive management practices vary considerably among Canadian dairy farms and decisions are associated with farm-level factors, including region, herd size, and barn type, as well as producer-level factors, such as age, managerial role, and education level.

Key words: dairy cow, Canada, management, reproduction

\section{INTRODUCTION}

Reproductive practices often vary depending on the producer's goals and preferences, production level, herd health, and facility limitations. Given the complexity of reproductive management programs on dairy farms, practices are unique on most farms and protocols can even vary among management groups within a farm. On-farm decisions pertaining specifically to reproductive management are often based on tradition, labor, cost (Holmann et al., 1987), and reproductive performance results (Holman et al., 2011; Denis-Robichaud et al., 2018). However, producers are faced with more options as the industry transitions from reproductive management based on traditional methods to those involving more progressive technologies.

In a study involving 832 Canadian dairy farms, Denis-Robichaud et al. $(2016,2018)$ evaluated producers' attitudes and perceptions toward reproductive performance and the effects of various management strategies on insemination, pregnancy, and conception rates. Neves and LeBlanc (2015) explored 505 Canadian herds, specifically comparing the reproductive performance and management of herds with and without automated activity-monitoring (AAM) systems. Each of these groups found that reproductive performance was the main factor influencing decisions. When adopting certain practices, producers were most influenced by insemination, conception, and pregnancy risk outcomes compared with other factors, such as economic benefit, the opportunity to monitor health, labor availability, or consumer perception. However, questions remain about 
how certain demographic factors may influence variation in the use of different reproductive management practices by producers.

In the United States, the National Animal Health Monitoring System regularly conducts national studies and provides data on the health and management of livestock industries (USDA-APHIS, 2017). Comparable to the National Animal Health Monitoring System Dairy Study in 2014, the Canadian National Dairy Study (NDS) 2015 was designed to target all licensed Canadian producers and gather information on the health and management of dairy cattle (Bauman et al., 2016). Based on a large survey offered to all producers and follow-up visits to a subset of respondent herds, the NDS generated data on herd demographics, biosecurity, animal care and welfare, calf health (Renaud et al., 2017), reproductive management, and milk quality (Belage et al., 2017; Bauman et al., 2018). The objectives of our study were to characterize the use of various reproductive management practices on Canadian dairy farms and describe differences based on regional and demographic variables.

\section{MATERIALS AND METHODS}

\section{Questionnaire Design}

Data were obtained through a cross-sectional survey of the Canadian dairy cattle industry in the form of a comprehensive questionnaire (Bauman et al., 2016). The questionnaire was accessible from March 1 to April 30, 2015, and all licensed dairy producers received a mailed letter of invitation to participate. Interested producers had several options to access and complete the questionnaire. The letter of invitation outlined the scope of the study and contained details about how to respond. Producers could complete the survey online using the Qualtrics platform (https://www.qualtrics.com/, Provo, UT), over the phone with a research assistant, or using a paper copy that was mailed to them. The questionnaire was offered in both English and French and is available online (http://www.nationaldairystudy.ca/ the-study; National Dairy Study, 2015). The English version of the survey can also be found in Supplemental File S1 (https://doi.org/10.3168/jds.2018-14683). Confidentiality was maintained through assignment of unique codes to each farm by the 10 provincial milk marketing boards. Study coordinators and research assistants did not have access to producer contact information. Producers also had the option to volunteer their herd production information to be confidentially provided by their provincial marketing boards. To increase the response rate, an incentive was awarded to the first 250 respondents, in the form of a $\$ 20$ gift card.
Demographic and milk shipment data for respondents and nonrespondents was also anonymized and provided by the provincial marketing boards.

The questionnaire was designed in response to a needs assessment conducted in 2014 involving Canadian dairy industry stakeholders (Bauman et al., 2016). Collaborators from the University of Guelph (Guelph, Ontario, Canada), University of Saskatchewan (Saskatoon, Saskatchewan, Canada), University of Calgary (Calgary, Alberta, Canada), Université de Montréal (St. Hyacinthe, Quebec, Canada), and University of Prince Edward Island (Charlottetown, Prince Edward Island, Canada) formulated questions focused on the 5 main management and disease priorities. A research advisory group of dairy producers, government representatives, veterinarians, and bilingual stakeholders modified, refined, and pretested the questionnaire before circulation. The final survey consisted of 189 questions pertaining to respondent and farm background information, herd dynamics, biosecurity, disease prevalence, calf health, animal welfare, milking practices, reproduction, and internet use. Relating specifically to reproduction, there were 24 questions regarding breeding methods, the use of natural service (NSV) and AI, estrus detection methods, hormonal protocols, and pregnancy diagnosis.

Ethics approval was obtained from all collaborating universities: University of Calgary (REB\#14-2481), University of Guelph (REB\#14DC025), Université de Montréal (15-007-CERES-D), and University of Prince Edward Island (REB\#6006095). Written consent was obtained from all producers who participated in the survey.

\section{Statistical Analyses}

Responses from paper questionnaires and telephone interviews were manually entered by research assistants into the Qualtrics platform. Data were exported from Qualtrics to Microsoft Excel (Microsoft Corporation, Redmond, WA) for cleaning, validation, and preliminary analysis. All statistical analyses were performed using SAS 9.4 (SAS Institute Inc., Cary, NC). Distributions and descriptive statistics were generated for each of the independent demographic variables and the dependent reproductive management variables. The Shapiro-Wilk test was used to evaluate normality with a $P$-value $<0.05$ indicating normal distribution. Milking herd size did not meet normality assumptions and thus was categorized as small ( $\leq 38$ cows), medium (39 to 85 cows), or large ( $\geq 86$ cows) based on the lower and upper quartiles of the data. Respondent age was categorized as $\leq 29,30$ to 59 , and $\geq 60$ yr, and respondent's level of education was categorized as primary, 
high school, postsecondary, or graduate school. Region was defined as western (provinces of British Columbia, Alberta, Saskatchewan, and Manitoba), Ontario, Quebec, or Atlantic (provinces of Prince Edward Island, Nova Scotia, New Brunswick, and Newfoundland). Scatter plots were constructed for continuous variables and outliers were evaluated and removed if deemed to be implausible. The dependent outcome variables investigated were estrus detection method for first insemination of cows, estrus detection method for repeat inseminations of cows, estrus detection method for heifers, breeding method, and method of pregnancy diagnosis. Questions regarding use of estrus detection methods were answered on a percentage attribution basis. To determine the primary method of estrus detection, herds were categorized based on which method they used for $>50 \%$ of inseminations. If a herd did not use one method $>50 \%$ of the time, they were assigned to a group that used a combination of methods (DenisRobichaud et al., 2016). Estrus detection was categorized into visual, AAM, hormonal synchronization, other, and a combination of detection methods. Other practices included the use of a bull, teaser steer, heat mount detectors, or hormone measurement in milk or blood. The person who performed $>50 \%$ of inseminations was designated the primary inseminator. If a farm did not use one inseminator $>50 \%$ of the time, they were recorded as using a combination of inseminators.

Weighted proportions were calculated based on the NDS response rate of each region (Atlantic, Ontario, Quebec, and Western), compared with the number of licensed producers according to the provincial milk marketing boards. Standard errors (SE) were calculated using the formula $\operatorname{SE}(\hat{p})=\sqrt{\hat{p} \hat{q} / n}$, where $p$ is the sample proportion, $q$ is $1-p$, and $n$ is the sample number. Simple associations were tested using Chi-squared tests with a significance level of $P<0.05$. If $>20 \%$ of cells in contingency tables had expected frequencies $<5$, Fish- er's exact tests with a significance level of $P<0.05$ were used. For all variables with more than 2 levels, univariable logistic regression models (GLIMMIX) were constructed to evaluate pairwise differences with a Bonferroni adjustment for multiple comparisons.

\section{RESULTS}

\section{Sampling and Respondent Characteristics}

The survey was sent to 11,664 active producers as identified by the provincial milk marketing boards in late 2014. Of the 11,025 licensed producers in 2015, 1,373 responded to the survey, representing a response rate of $12.5 \%$. They completed the survey in various ways, with $5.8 \%$ of respondents $(\mathrm{n}=79)$ completing the questionnaire over the telephone, $16.3 \%(\mathrm{n}=224)$ mailed paper copies, and $77.9 \%(\mathrm{n}=1,070)$ online. Of those who participated and started the questionnaire, 1,124 respondents completed the herd characteristics and demographics section and 1,062 respondents completed the survey in full. In particular, 1,052 respondents completed the section on reproduction in full. The national average of dairy producers enrolled in milk recording in 2015 was $78 \%$, whereas $86 \%$ of respondent farms were enrolled in DHIA milk recording through CanWest DHI (Guelph, Ontario, Canada) or Valacta (Saint-Anne-de-Bellevue, Quebec, Canada). Response rates for each province and corresponding region are in Table 1. Figure 1 illustrates the distribution of barn type of respondents compared with the distribution of barn type across all herds in the national population in 2015. The average milking herd size was 77 cows $[$ median $=54$, interquartile range $(\mathbf{I Q R})=38$ to 86$]$ and the average milk production was $9,179 \mathrm{~kg} / \mathrm{cow}$ per $305 \mathrm{~d}$ (median $=9,666, \mathrm{IQR}=8,548$ to 10,415 ). Table 2 outlines the distribution of demographic variables of respondents.

Table 1. Number of respondents, number of licensed dairy producers, and response rate for each province and region in the Canadian National Dairy Study 2015

\begin{tabular}{lccc}
\hline Region or province & $\begin{array}{c}\text { Number of } \\
\text { respondents }\end{array}$ & $\begin{array}{c}\text { Number of } \\
\text { licensed producers }\end{array}$ & $\begin{array}{c}\text { Response } \\
\text { rate (\%) }\end{array}$ \\
\hline Atlantic & 87 & 633 & 13.7 \\
New Brunswick & 27 & 204 & 13.2 \\
Nova Scotia & 27 & 225 & 12.0 \\
Prince Edward Island & 27 & 177 & 15.3 \\
Newfoundland and Labrador & 6 & 27 & 22.2 \\
Ontario & 401 & 3,232 & 12.4 \\
Quebec & 509 & 5,660 & 9.0 \\
Western & 160 & 1,500 & 10.7 \\
British Columbia & 48 & 496 & 9.7 \\
Alberta & 56 & 549 & 10.2 \\
Saskatchewan & 11 & 156 & 7.1 \\
Manitoba & 45 & 299 & 15.1 \\
\hline
\end{tabular}


Because response rates to the NDS varied by region, the responses were weighted proportionately to the number of herds in each region using their respective response rates. The weighted distributions and standard errors of reproductive practices involving estrus detection, hormonal synchronization, breeding methods, and pregnancy diagnosis and confirmation are presented in Table 3.

\section{Estrus Detection}

Methods of estrus detection for first and repeat inseminations in lactating cows differed by herd size, barn type, region, organic production, breeding method, and age of respondent (Tables 4 and 5), and relationships were similar for first and repeat inseminations. Respondents' education level was not associated with estrus detection methods for first or repeat inseminations ( $P=0.49$ and $P=0.10$, respectively). Seventy-six percent of farms $(\mathrm{n}=798)$ used the same method of estrus detection for all inseminations in cows, whereas the rest of the farms used different methods for first and subsequent inseminations. On farms that used any percentage of visual estrus detection $>0 \%$ in cows ( $\mathrm{n}$
$=934)$, respondents reported observing for estrus on average 3.6 times per day (median $=3, \mathrm{IQR}=2$ to 4 ), for an average of $44.5 \mathrm{~min} / \mathrm{d}$ (median $=20, \mathrm{IQR}=15$ to 45$)$. Estrus detection was the only task performed at this time in $29.1 \%(\mathrm{n}=275)$ of herds.

The distribution of estrus detection methods for nulliparous heifers differed by herd size, barn type, region, and breeding method (Table 6). Organic production, education level, and age of respondent were not significantly associated with the estrus detection method used for heifers $(P=0.07, P=0.08$, and $P=0.41$, respectively). On farms that used any percentage of visual estrus detection $>0 \%$ in heifers $(\mathrm{n}=918)$, respondents reported observing for estrus on average 2.9 times per day (median $=2, \mathrm{IQR}=2$ to 3.5 ), for an average of 23.5 min per day (median $=15, \mathrm{IQR}=10$ to 30 ). Estrus detection was the only task performed at this time in $36.1 \%$ of herds $(\mathrm{n}=333)$.

\section{Breeding Method}

Breeding method varied significantly by herd size, barn type, region, and education level (Table 7). Neither organic production nor age of the respondent was

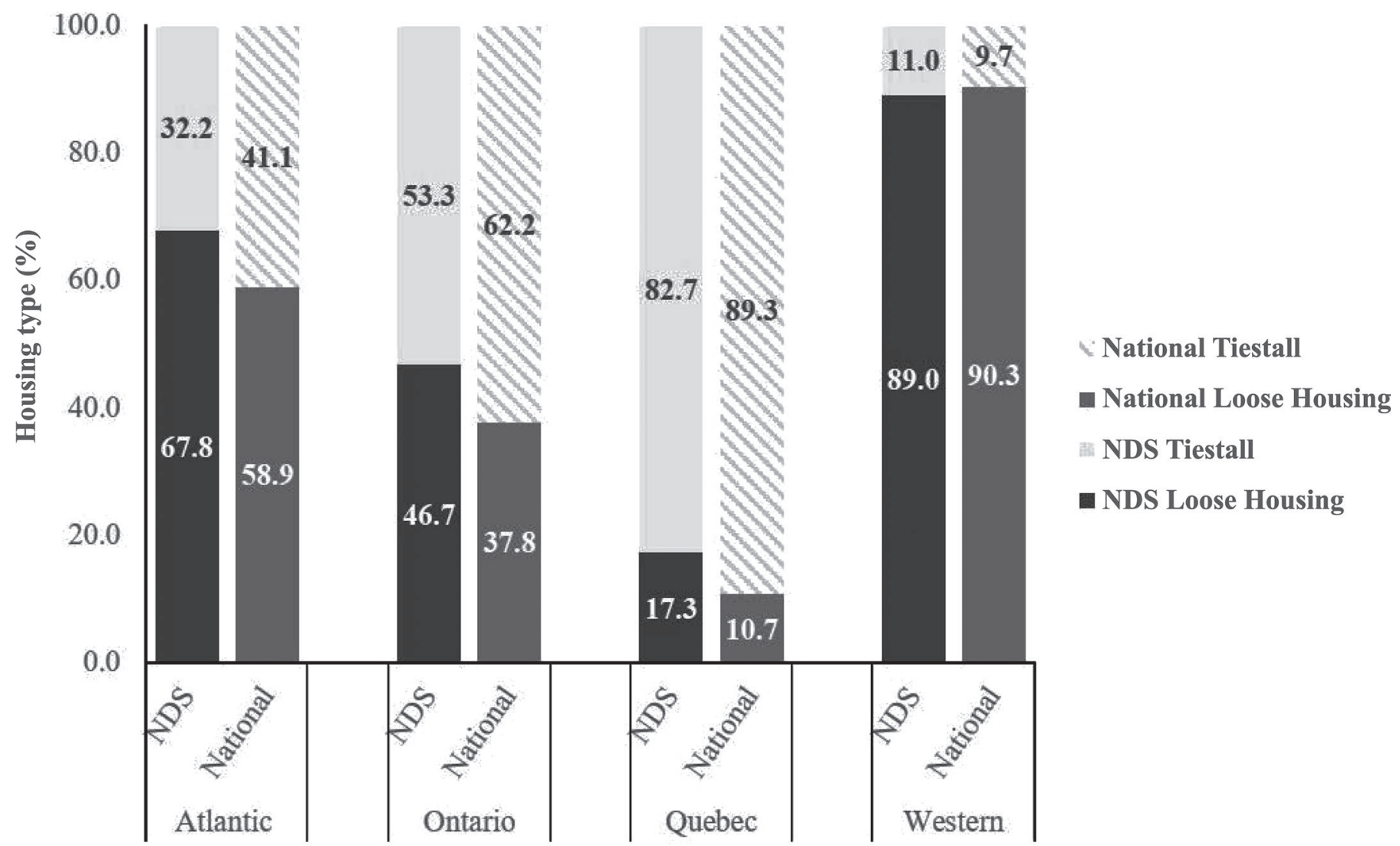

Figure 1. Representation comparing the percentages of housing types in 1,157 herds from the 2015 National Dairy Study (NDS) and 11,025 herds from the national population (National) in Canada. 
Table 2. Number, proportion, and standard error of respondents in the Canadian National Dairy Study 2015 described by various demographic variables

\begin{tabular}{|c|c|c|c|}
\hline Variable & Number & Proportion (\%) & SE \\
\hline \multicolumn{4}{|c|}{ Herd size $(\mathrm{n}=1,079)$} \\
\hline Large & 267 & 24.8 & 2.6 \\
\hline Medium & 542 & 50.2 & 2.1 \\
\hline Small & 270 & 25.0 & 2.6 \\
\hline \multicolumn{4}{|c|}{ Barn type $(\mathrm{n}=1,154)$} \\
\hline Freestall & 442 & 38.3 & 2.3 \\
\hline Tiestall & 674 & 58.4 & 1.9 \\
\hline Other & 38 & 3.3 & 2.9 \\
\hline \multicolumn{4}{|c|}{ Milking style $(\mathrm{n}=1,151)$} \\
\hline Pipeline & 681 & 59.2 & 1.9 \\
\hline Parlor & 340 & 29.5 & 2.5 \\
\hline Robotic system & 130 & 11.3 & 2.8 \\
\hline \multicolumn{4}{|l|}{ Region $(\mathrm{n}=1,157)$} \\
\hline Atlantic & 87 & 7.5 & 2.8 \\
\hline Ontario & 401 & 34.7 & 2.4 \\
\hline Quebec & 509 & 44.0 & 2.2 \\
\hline Western & 160 & 13.8 & 2.7 \\
\hline \multicolumn{4}{|c|}{ Organic $(\mathrm{n}=1,156)$} \\
\hline No & 1,121 & 97.0 & 0.5 \\
\hline Yes & 35 & 3.0 & 2.9 \\
\hline \multicolumn{4}{|c|}{ Respondent title $(\mathrm{n}=1,153)$} \\
\hline Owner & 1,006 & 87.1 & 1.1 \\
\hline Manager & 83 & 7.2 & 2.8 \\
\hline Farm employee & 27 & 2.3 & 2.9 \\
\hline Other & 39 & 3.4 & 2.9 \\
\hline \multicolumn{4}{|c|}{ Age of respondent $(\mathrm{n}=1,153)$} \\
\hline $0-29$ yr & 166 & 14.4 & 2.7 \\
\hline $30-59$ yr & 898 & 77.9 & 1.4 \\
\hline $60+\mathrm{yr}$ & 89 & 7.7 & 2.8 \\
\hline \multicolumn{4}{|c|}{ Education level of respondent $(\mathrm{n}=1,153)$} \\
\hline Graduate & 21 & 1.8 & 2.9 \\
\hline Post secondary & 730 & 63.3 & 1.8 \\
\hline High school & 285 & 24.7 & 2.6 \\
\hline Primary school & 117 & 10.2 & 2.8 \\
\hline
\end{tabular}

associated with the breeding method $(P=0.26$ and $P$ $=0.46$, respectively).

\section{Pregnancy Diagnosis and Confirmation}

The distribution of pregnancy diagnosis method differed by herd size, barn type, region, and organic production (Table 8). Neither education level nor age of the respondent were related to the method of pregnancy diagnosis $(P=0.05$ and $P=0.10$, respectively). The minimum interval after AI for pregnancy diagnosis was $<30 \mathrm{~d}$ on $15.6 \%$ of farms $(\mathrm{n}=162)$, between 30 and $34 \mathrm{~d}$ on $48.4 \%(\mathrm{n}=503), 35$ and $39 \mathrm{~d}$ on $21.3 \%$ $(\mathrm{n}=222), 40$ and $45 \mathrm{~d}$ on $8.6 \%(\mathrm{n}=90)$, and $>45 \mathrm{~d}$ on $6.1 \%$ of farms $(\mathrm{n}=63)$. After pregnancy diagnosis, $68.5 \%$ of farms routinely confirmed pregnancies.

\section{DISCUSSION}

The use of reproductive management practices differs among Canadian dairy farms and is influenced by farm and producer-level factors. Compared with other studies, our study is the first to recognize how demo- graphic characteristics may be directly associated with implementation of certain reproductive management practices. Denis-Robichaud et al. (2016) identified factors affecting herd-level measures of reproductive performance on Canadian dairy farms. We noted many similarities between that study and the present, but we now shed light on management differences among regions, herd demographics, and respondent characteristics.

Figure 1 demonstrates that the population in our study is fairly representative of the distribution of housing types in Canadian dairy herds (Bauman et al., 2018). Although regional differences were noted in response rates, the differences were small and the weighted estimates for reproductive practices differed only slightly from the crude proportions. Selection bias was minimized as both DHIA and non-DHIA herds were invited to participate. A slight response bias may have occurred, due to a higher proportion of farms enrolled in milk recording and a lower proportion of tiestall respondents compared with the national averages; however, milk production and milk quality data analyzed from the same survey suggest no meaningful 
differences between respondents and nonrespondents (Belage et al., 2017; Bauman et al., 2018).

We found a wide variety of estrus detection methods implemented across Canadian farms. The demographic associations with detection methods were generally similar for cows and heifers. Visual estrus detection was most frequently used and means the producer or employee must physically observe estrous behavior, which can be very labor intensive and can be more difficult on large farms (Diskin and Sreenan, 2000). Overall, farms used a higher proportion of visual detection in heifers than cows, although, on average, producers spent less time observing estrus behavior in heifers. Farms in the western provinces used a higher proportion of AAM than in other regions, likely due to the increased number of large herds (60\%) and freestalls (77\%) in the

Table 3. Number, crude proportion, crude SE, weighted proportion, and weighted SE of farms in the Canadian National Dairy Study 2015 using various reproductive management practices

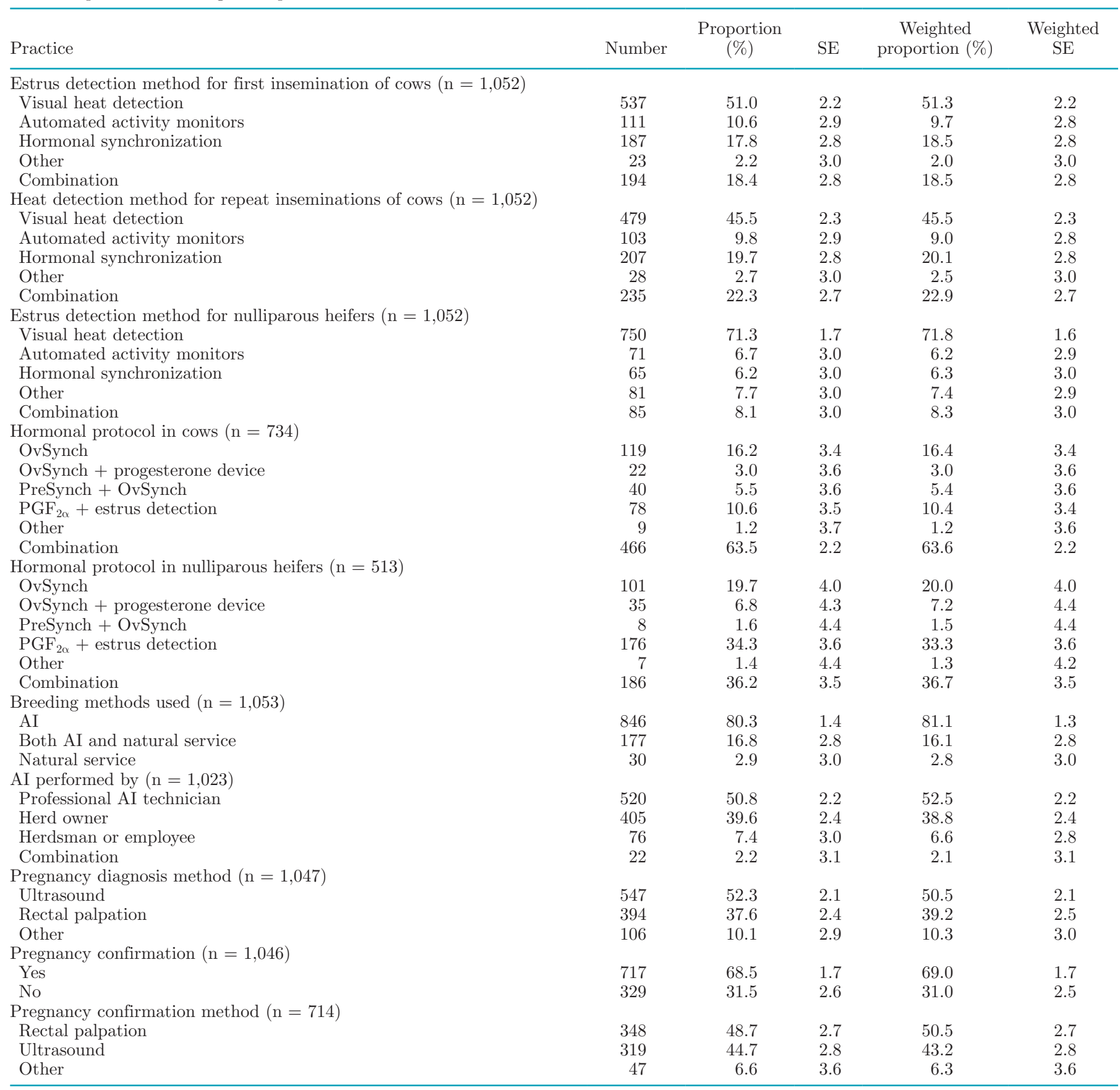


Table 4. Simple associations of herd size, barn type, region, organic production, breeding method, and respondent age with the primary estrus detection method used for $>50 \%$ of first inseminations of lactating cows in 1,052 herds participating in the Canadian National Dairy Study $2015^{1}$

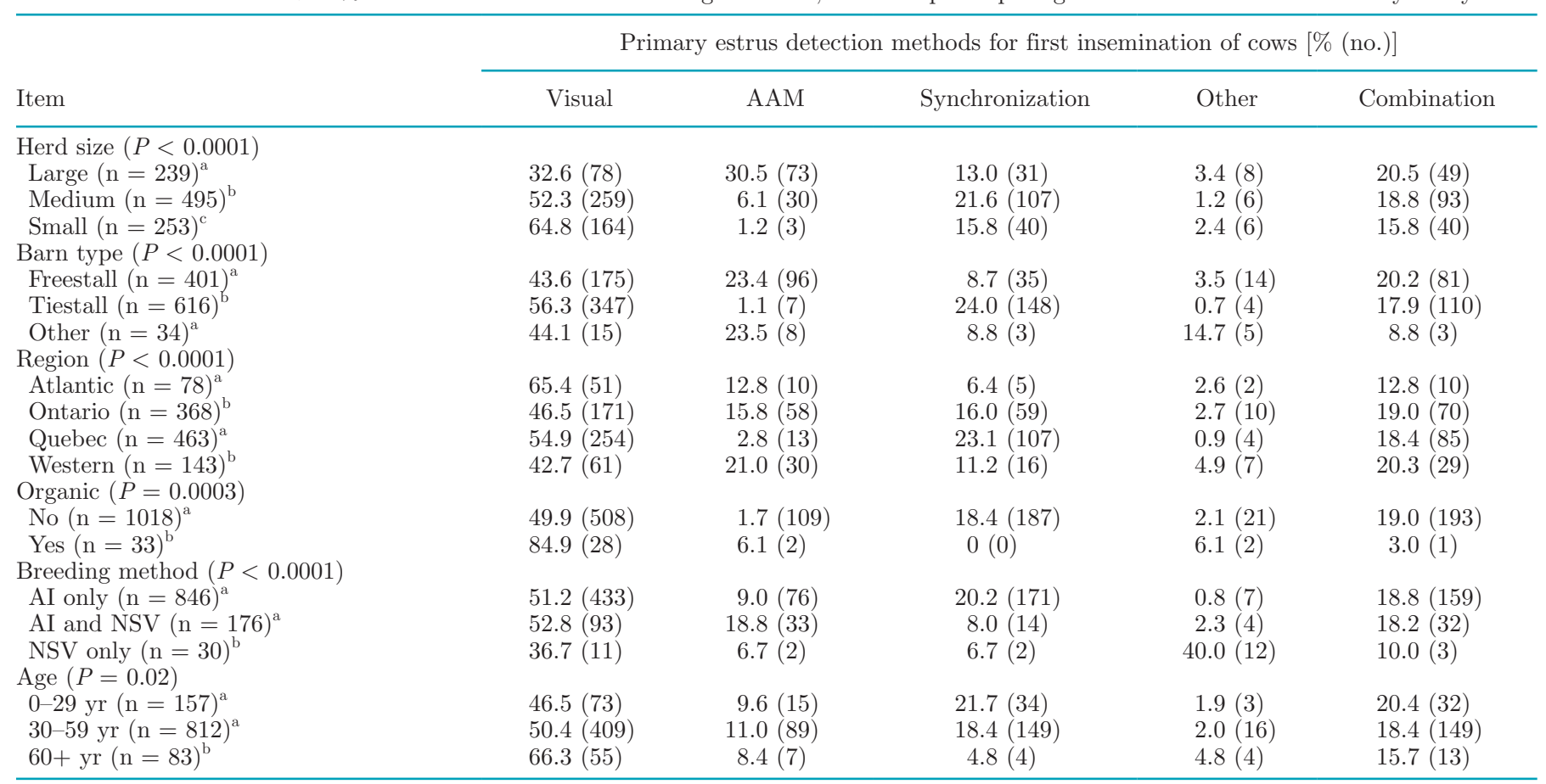

${ }^{\mathrm{a}-\mathrm{c}}$ Proportions not sharing the same superscript are significantly different $(P<0.05)$ from each other after Bonferroni adjustment.

${ }^{1} \mathrm{NSV}=$ natural service; AAM $=$ automated activity monitors.

Table 5. Simple associations of herd size, barn type, region, organic production, breeding method, and respondent age with the primary estrus detection method used for $>50 \%$ of repeat inseminations of lactating cows in 1,052 herds participating in the Canadian National Dairy Study $2015^{1}$

Primary estrus detection methods for repeat inseminations [\% (no.)]

\begin{tabular}{|c|c|c|c|c|c|}
\hline \multirow[b]{2}{*}{ Item } & \\
\hline & Visual & $\mathrm{AAM}$ & Synchronization & Other & Combination \\
\hline \multicolumn{6}{|l|}{ Herd size $(P<0.0001)$} \\
\hline Large $(\mathrm{n}=239)^{\mathrm{a}}$ & $31.0(74)$ & $26.0(62)$ & $12.1(29)$ & $4.2(10)$ & $26.8(64)$ \\
\hline Medium $(\mathrm{n}=495)^{\mathrm{b}}$ & $47.5(235)$ & $6.3(31)$ & $22.2(110)$ & $1.6(8)$ & $22.4(111)$ \\
\hline Small $(\mathrm{n}=253)^{\mathrm{b}}$ & $54.9(139)$ & $2.0(5)$ & $21.7(55)$ & $2.8(7)$ & $18.6(47)$ \\
\hline \multicolumn{6}{|l|}{ Barn type $(P<0.0001)$} \\
\hline Freestall $(\mathrm{n}=401)^{\mathrm{a}}$ & $39.9(160)$ & $22.0(88)$ & $9.7(39)$ & $3.7(15)$ & $24.7(99)$ \\
\hline Tiestall $(\mathrm{n}=616)^{b}$ & $49.5(304)$ & $1.3(8)$ & $26.8(165)$ & $1.1(7)$ & $21.4(132)$ \\
\hline Other $(\mathrm{n}=34)^{\mathrm{a}}$ & $44.1(15)$ & $20.6(7)$ & $5.9(2)$ & $17.7(6)$ & $11.8(4)$ \\
\hline \multicolumn{6}{|l|}{ Region $(P<0.0001)$} \\
\hline Atlantic $(\mathrm{n}=78)^{\mathrm{a}}$ & $65.4(51)$ & $11.5(9)$ & $6.4(5)$ & $3.9(3)$ & $12.8(10)$ \\
\hline Ontario $(\mathrm{n}=368)^{\mathrm{b}}$ & $41.9(154)$ & $14.4(53)$ & $20.4(75)$ & $3.0(11)$ & $20.4(75)$ \\
\hline Quebec $(\mathrm{n}=463)^{\mathrm{c}}$ & $46.9(217)$ & $2.8(13)$ & $22.9(106)$ & $1.5(7)$ & $25.9(120)$ \\
\hline Western $(\mathrm{n}=143)^{\mathrm{b}}$ & $39.9(57)$ & $19.6(28)$ & $14.7(21)$ & $4.9(7)$ & $21.0(30)$ \\
\hline \multicolumn{6}{|l|}{ Organic $(P=0.0002)$} \\
\hline No $(\mathrm{n}=1018)^{\mathrm{a}}$ & $44.3(451)$ & $9.9(101)$ & $20.3(207)$ & $2.6(26)$ & $22.9(233)$ \\
\hline $\operatorname{Yes}(\mathrm{n}=33)^{\mathrm{b}}$ & $81.8(27)$ & $6.1(2)$ & $0(0)$ & $6.1(2)$ & $6.1(2)$ \\
\hline \multicolumn{6}{|c|}{ Breeding method $(P<0.0001)$} \\
\hline AI only $(\mathrm{n}=846)^{\mathrm{a}}$ & $46.1(390)$ & $9.1(77)$ & $21.0(178)$ & $1.0(8)$ & $22.8(193)$ \\
\hline $\mathrm{AI}$ and $\mathrm{NSV}(\mathrm{n}=176)^{\mathrm{a}}$ & $44.9(79)$ & $14.2(25)$ & $14.2(25)$ & $4.0(7)$ & $22.7(40)$ \\
\hline NSV only $(\mathrm{n}=30)^{\mathrm{b}}$ & $33.3(10)$ & $3.3(1)$ & $13.3(4)$ & $43.3(13)$ & $6.7(2)$ \\
\hline \multicolumn{6}{|l|}{ Age $(P=0.004)$} \\
\hline $0-29$ yr $(\mathrm{n}=157)^{\mathrm{ab}}$ & $40.8(64)$ & $9.6(15)$ & $26.1(41)$ & $2.6(4)$ & $21.0(33)$ \\
\hline $30-59$ yr $(\mathrm{n}=812)^{\mathrm{ac}}$ & $45.4(369)$ & $10.0(81)$ & $19.3(157)$ & $2.1(17)$ & $23.2(188)$ \\
\hline $60+\operatorname{yr}(n=83)^{b c}$ & $55.4(46)$ & $8.4(7)$ & $10.8(9)$ & $8.4(7)$ & $16.9(14)$ \\
\hline
\end{tabular}

${ }^{a-c}$ Proportions not sharing the same superscript are significantly different $(P<0.05)$ from each other after Bonferroni adjustment.

${ }^{1} \mathrm{NSV}=$ natural service; AAM $=$ automated activity monitors. 
Table 6. Simple associations of herd size, barn type, region, and breeding method with the primary estrus detection method used for $>50 \%$ of inseminations of nulliparous heifers in 1,052 herds participating in the Canadian National Dairy Study 2015

\begin{tabular}{|c|c|c|c|c|c|}
\hline \multirow[b]{2}{*}{ Item } & \multicolumn{5}{|c|}{ Primary estrus detection methods for insemination of heifers [\% (no.)] } \\
\hline & Visual & AAM & Synchronization & Other & Combination \\
\hline Large $(\mathrm{n}=239)^{\mathrm{a}}$ & $52.3(125)$ & $20.1(48)$ & $6.3(15)$ & $13.4(32)$ & $8.0(19)$ \\
\hline Medium $(\mathrm{n}=495)^{\mathrm{b}}$ & $75.6(374)$ & $3.6(18)$ & $6.5(32)$ & $5.9(29)$ & $8.5(42)$ \\
\hline Small $(\mathrm{n}=253)^{\mathrm{b}}$ & $81.4(206)$ & $1.2(3)$ & $5.1(13)$ & $5.5(14)$ & $6.7(17)$ \\
\hline \multicolumn{6}{|l|}{ Barn type $(P<0.0001)$} \\
\hline Other $(\mathrm{n}=34)^{\mathrm{a}}$ & $52.9(18)$ & $8.8(3)$ & $2.9(1)$ & $35.3(12)$ & $0(0)$ \\
\hline \multicolumn{6}{|l|}{ Region $(P<0.0001)$} \\
\hline Atlantic $(\mathrm{n}=78)^{\mathrm{ab}}$ & $78.2(61)$ & $6.4(5)$ & $5.1(4)$ & $10.3(8)$ & $0(0)$ \\
\hline Ontario $(\mathrm{n}=368)^{\mathrm{a}}$ & $69.3(255)$ & $9.8(36)$ & $6.0(22)$ & $7.6(28)$ & $7.3(27)$ \\
\hline Quebec $(\mathrm{n}=463)^{\mathrm{b}}$ & $78.8(365)$ & $1.7(8)$ & $7.1(33)$ & $3.5(16)$ & $8.9(41)$ \\
\hline Western $(\mathrm{n}=143)^{\mathrm{c}}$ & $48.3(69)$ & $15.4(22)$ & $4.2(6)$ & $20.3(29)$ & $11.9(17)$ \\
\hline \multicolumn{6}{|c|}{ Breeding method $(P<0.0001)$} \\
\hline
\end{tabular}

${ }^{\mathrm{a}-\mathrm{c}}$ Proportions not sharing the same superscript are significantly different $(P<0.05)$ from each other after Bonferroni adjustment.

${ }^{1} \mathrm{NSV}=$ natural service; AAM $=$ automated activity monitors.

western provinces, which were characteristics that were highly correlated with the use of AAM. Automated activity systems are most effective when cows are loosely housed (Felton et al., 2012) and can freely express an increase in physical activity (Britt et al., 1986; Diskin and Sreenan, 2000). Farms in Quebec used less AAM but used the highest proportion of hormonal synchronization. This could be explained by the fact that Quebec has more small and medium herds and a very large proportion of tiestall herds (83\%), where AAM cannot accurately detect differences in physical activity associated with estrus behavior (Felton et al., 2012). This also agrees with results by Denis-Robichaud et al. (2018), who showed that a higher proportion of tiestall respondents declared "it is difficult to identify cows in heat" and who therefore used higher levels of synchronization. The proportion of freestall farms using AAM in the current study was lower than the $44 \%$ found by

Table 7. Simple associations of herd size, barn type, region, and respondent's level of education with breeding method in 1,053 herds participating in the Canadian National Dairy Study 2015

\begin{tabular}{|c|c|c|c|}
\hline \multirow[b]{2}{*}{ Item } & \multicolumn{3}{|c|}{ Breeding method, [\% (no.)] } \\
\hline & AI only & Both $\mathrm{AI}$ and $\mathrm{NSV}^{1}$ & NSV only \\
\hline \multicolumn{4}{|l|}{ Herd size $(P<0.0001)$} \\
\hline Large $(\mathrm{n}=240)^{\mathrm{a}}$ & $67.5(162)$ & $27.5(66)$ & $5(12)$ \\
\hline Medium $(\mathrm{n}=495)^{\mathrm{b}}$ & $85.1(421)$ & $13.1(65)$ & $1.8(9)$ \\
\hline Small $(\mathrm{n}=253)^{\mathrm{b}}$ & $85.0(215)$ & $12.3(31)$ & $2.8(7)$ \\
\hline \multicolumn{4}{|l|}{ Barn type $(P<0.0001)$} \\
\hline Freestall $(\mathrm{n}=402)^{\mathrm{a}}$ & $70.7(284)$ & $25.1(101)$ & $4.2(17)$ \\
\hline Tiestall $(\mathrm{n}=616)^{\mathrm{b}}$ & $87.8(541)$ & $11.0(68)$ & $1.1(7)$ \\
\hline Other $(\mathrm{n}=34)^{\mathrm{c}}$ & $58.8(20)$ & $23.5(8)$ & $17.7(6)$ \\
\hline \multicolumn{4}{|l|}{ Region $(P<0.0001)$} \\
\hline Atlantic $(\mathrm{n}=78)^{\mathrm{a}}$ & $74.4(58)$ & $24.4(19)$ & $1.3(1)$ \\
\hline Ontario $(\mathrm{n}=369)^{\mathrm{a}}$ & $80.5(297)$ & $17.9(66)$ & $1.6(6)$ \\
\hline Quebec $(\mathrm{n}=463)^{\mathrm{b}}$ & $89.0(412)$ & $10.2(47)$ & $0.9(4)$ \\
\hline Western $(\mathrm{n}=143)^{\mathrm{c}}$ & $55.2(79)$ & $31.5(45)$ & $13.3(19)$ \\
\hline \multicolumn{4}{|l|}{ Education level $(P<0.0001)$} \\
\hline Graduate $(\mathrm{n}=20)^{\mathrm{abc}}$ & $90.0(18)$ & $10.0(2)$ & $0(0)$ \\
\hline Post secondary $(\mathrm{n}=663)^{\mathrm{a}}$ & $83.3(552)$ & $15.7(104)$ & $1.1(7)$ \\
\hline High school $(\mathrm{n}=255)^{\mathrm{bd}}$ & $75.7(193)$ & $21.6(55)$ & $2.8(7)$ \\
\hline Primary school $(\mathrm{n}=111)^{\mathrm{cd}}$ & $73.0(81)$ & $12.6(14)$ & $14.4(16)$ \\
\hline
\end{tabular}


Table 8. Simple associations of herd size, barn type, region, and organic production with method of pregnancy diagnosis in 1,047 herds participating in the Canadian National Dairy Study 2015

\begin{tabular}{|c|c|c|c|}
\hline \multirow[b]{2}{*}{ Item } & \multicolumn{3}{|c|}{ Pregnancy diagnosis $[\%$ (no.)] } \\
\hline & Ultrasound & Rectal palpation & Other \\
\hline \multicolumn{4}{|l|}{ Herd size $(P<0.0001)$} \\
\hline Large $(\mathrm{n}=238)^{\mathrm{a}}$ & $65.1(155)$ & $26.5(63)$ & $8.4(20)$ \\
\hline Medium $(\mathrm{n}=494)^{\mathrm{b}}$ & $51.0(252)$ & $40.9(202)$ & $8.1(40)$ \\
\hline Small $(\mathrm{n}=250)^{\mathrm{c}}$ & $41.2(103)$ & $43.6(109)$ & $15.2(38)$ \\
\hline \multicolumn{4}{|l|}{ Barn type $(P<0.0001)$} \\
\hline Freestall $(\mathrm{n}=399)^{\mathrm{a}}$ & $62.4(249)$ & $29.6(118)$ & 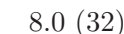 \\
\hline Tiestall $(\mathrm{n}=613)^{\mathrm{b}}$ & $46.3(284)$ & $42.6(261)$ & $11.1(68)$ \\
\hline Other $(\mathrm{n}=34)^{\mathrm{b}}$ & $41.2(14)$ & $44.1(15)$ & $14.7(5)$ \\
\hline \multicolumn{4}{|l|}{ Region $(P<0.0001)$} \\
\hline Atlantic $(\mathrm{n}=77)^{\mathrm{ab}}$ & $58.4(45)$ & $35.1(27)$ & $6.5(5)$ \\
\hline Ontario $(\mathrm{n}=366)^{\mathrm{a}}$ & $61.8(226)$ & $28.4(104)$ & $9.8(36)$ \\
\hline Quebec $(\mathrm{n}=461)^{\mathrm{c}}$ & $37.7(174)$ & $50.5(233)$ & $11.7(54)$ \\
\hline Western $(\mathrm{n}=143)^{\mathrm{b}}$ & $71.3(102)$ & $21.0(30)$ & $7.7(11)$ \\
\hline \multicolumn{4}{|l|}{ Organic $(P=0.007)$} \\
\hline No $(\mathrm{n}=1.013)^{\mathrm{a}}$ & $53.0(537)$ & $37.2(377)$ & $9.8(99)$ \\
\hline Yes $(\mathrm{n}=33)^{\mathrm{b}}$ & $27.3(9)$ & $51.5(17)$ & $21.2(7)$ \\
\hline
\end{tabular}

Neves and LeBlanc (2015). However, they suspected an over-representation due to the indication of special interest in AAM systems when recruiting respondents. Farms that exclusively used AI used a larger proportion of hormonal synchronization compared with those that used NSV. Producers are less likely to use synchronization when using a bull, as timing of insemination is extremely important (Cartmill et al., 2001) and can be managed more easily with AI. Older respondents used a higher proportion of visual detection and less hormonal synchronization or AAM compared with younger respondents. Holman et al. (2011) compared estrous detection methods individually and in combinations and found that combining visual detection and neck collar activity monitors produced the most accurate level of estrus detection. Conversely, according to Denis-Robichaud et al. (2016), farms that used hormonal synchronization or a combination of practices had higher insemination rates but no significant differences in pregnancy rate. These results show that, although some estrous detection methods may be superior to others, overall reproductive performance is a result of several management practices working together.

The method of insemination was influenced by herd size, barn type, region, and educational level. Large herds and those with freestall facilities used a much larger proportion of NSV compared with small herds or tiestalls in the current study. Although bulls can be equally as dangerous on any farm, our results suggest that using a bull for breeding may be more practical or efficient for large herds. We also hypothesized that differences in facility design may allow for easier handling and housing of bulls in freestalls when compared with tiestalls. The biggest regional difference was an association between western provinces using less $\mathrm{AI}$ and more NSV compared with all other regions. This could be a function of having larger herds and freestall herds, but also that some religious-based farm communities in the western region do not accept AI. Respondents with a primary school education were significantly less likely to use AI and more likely to inseminate exclusively using NSV when compared with those who received a post-secondary education. This could be a result of cultural influence in some communities, or that those of a lower education level may not be aware of the benefits of using AI (Funk, 2006). Results pertaining to age and education level of respondent should be interpreted carefully, as the possibility of bias exists due to whether the respondent was the owner, manager, or a farm employee. However, $94.3 \%$ of respondents were either the owner or manager, whom we assume are most involved in making decisions on the farm and therefore provide an accurate representation.

Pregnancy diagnosis has a great influence on reproductive efficiency, as early identification of nonpregnant cows will decrease the interval between inseminations (Fricke, 2002). Ultrasound was the most commonly employed means of pregnancy diagnosis among Canadian farms and was most heavily used on large farms and those with freestall housing. In contrast, Caraviello et al. (2006) reported that rectal palpation was the most commonly used method of pregnancy diagnosis on large commercial farms in the United States. The difference in results was likely due to their larger average herd size (613 vs. 77 cows in the current study), where rectal palpation may be more practical and economical. The 
incidence of pregnancy loss in high-producing dairy cattle is variable but can exceed $20 \%$ (Cartmill et al., 2001), with early embryonic loss ranging from 15 to 25\% (Moore et al., 2005). Rechecking cows around 60 d postbreeding identifies pregnancy loss (Fricke, 2002) and can identify fetal sex when using ultrasound technology (Quintela et al., 2011). With about one third of farms not rechecking to confirm pregnancy, it is possible that producers are not educated as to the benefit of confirmation or that it may not be practical on some farms. Interestingly, although more respondent farms used ultrasound as the preferred method for pregnancy diagnosis, rectal palpation was the most commonly used method for pregnancy confirmation.

\section{CONCLUSIONS}

Reproductive management practices vary considerably among Canadian dairy producers. Factors such as region, herd size, barn type, organic production, and age and education level of respondents may affect decisions involving estrus detection, insemination, and pregnancy diagnosis. It is likely that some geographic region and herd size associations may be confounded with barn type differences across the country. Understanding the factors associated with reproductive management practices helps to inform knowledge transfer and translation.

\section{ACKNOWLEDGMENTS}

We thank all Canadian dairy producers who participated in the National Dairy Study 2015 and all research assistants who input and processed data from the questionnaire. Thank you to the dairy stakeholders and researchers from the various veterinary colleges for their collaboration and support. This study was supported by the Dairy Research Cluster 2 Program, funded by Dairy Farmers of Canada (Ottawa, Ontario, Canada), Agriculture and Agri-Food Canada (Ottawa, Ontario, Canada), Canadian Dairy Commission (Ottawa, Ontario, Canada), and Natural Sciences and Engineering Research Council (Ottawa, Ontario, Canada).

\section{REFERENCES}

Bauman, C. A., H. Barkema, J. Dubuc, G. Keefe, and D. Kelton. 2016. Identifying management and disease priorities of Canadian dairy industry stakeholders. J. Dairy Sci. 99:10194-10203.
Bauman, C. A., H. W. Barkema, J. Dubuc, G. P. Keefe, and D. F. Kelton. 2018. Canadian National Dairy Study: Herd-level milk quality. J. Dairy Sci. 101:2679-2691.

Belage, E., S. Dufour, C. Bauman, A. Jones-Bitton, and D. Kelton. 2017. The Canadian National Dairy Study 2015-Adoption of milking practices in Canadian dairy herds. J. Dairy Sci. 100:3839 3849 .

Britt, J. H., R. G. Scott, J. D. Armstrong, and M. D. Whitacre. 1986. Determinants of estrous behavior in lactating Holstein cows. J. Dairy Sci. 69:2195-2202.

Caraviello, D. Z., K. A. Weigel, P. M. Fricke, M. C. Wiltbank, M. J. Florent, N. B. Cook, K. V. Nordlund, N. R. Zwald, and C. L. Rawson. 2006. Survey of management practices on reproductive performance of dairy cattle on large us commercial farms. J. Dairy Sci. 89:4723-4735.

Cartmill, J. A., S. Z. El-Zarkouny, B. A. Hensley, G. C. Lamb, and J. S. Stevenson. 2001. Stage of cycle, incidence, and timing of ovulation, and pregnancy rates in dairy cattle after three timed breeding protocols. J. Dairy Sci. 84:1051-1059.

Denis-Robichaud, J., R. Cerri, A. Jones-Bitton, and S. LeBlanc. 2016. Survey of reproduction management on Canadian dairy farms. J. Dairy Sci. 99:9339-9351.

Denis-Robichaud, J., R. Cerri, A. Jones-Bitton, and S. LeBlanc. 2018. Dairy producers' attitudes toward reproductive management and performance on Canadian dairy farms. J. Dairy Sci. 101:850-860.

Diskin, M. G., and J. M. Sreenan. 2000. Expression and detection of oestrus in cattle. Reprod. Nutr. Dev. 40:481-491.

Felton, C. A., M. G. Colazo, P. Ponce-Barajas, C. J. Bench, and D. J. Ambrose. 2012. Dairy cows continuously-housed in tie-stalls failed to manifest activity changes during estrus. Can. J. Anim. Sci. 92:189-196.

Fricke, P. M. 2002. Scanning the future-Ultrasonography as a reproductive management tool for dairy cattle. J. Dairy Sci. 85:19181926.

Funk, D. A. 2006. Major advances in globalization and consolidation of the artificial insemination industry. J. Dairy Sci. 89:1362-1368.

Holman, A., J. Thompson, J. E. Routly, J. Cameron, D. N. Jones, R. F. Smith, and H. Dobson. 2011. Comparison of oestrus detection methods in dairy cattle. Vet. Rec. 169:47.

Holmann, F. J., R. W. Blake, and C. R. Shumway. 1987. Economic evaluation of fourteen methods of estrous detection. J. Dairy Sci. 70:186-194.

Moore, D. A., M. W. Overton, R. C. Chebel, M. L. Truscott, and R. H. BonDurant. 2005. Evaluation of factors that affect embryonic loss in dairy cattle. J. Am. Vet. Med. Assoc. 226:1112-1118.

National Dairy Study. 2015. The Study. Accessed May 15, 2018. http: //www.nationaldairystudy.ca/the-study.

Neves, R. C., and S. LeBlanc. 2015. Reproductive management practices and performance of Canadian dairy herds using automated activity-monitoring systems. J. Dairy Sci. 98:2801-2811.

Quintela, L. A., J. J. Becerra, C. C. Pérez-Marín, M. Barrio, J. Cainzos, A. Prieto, C. Díaz, and P. G. Herradón. 2011. Fetal gender determination by first-trimester ultrasound in dairy cows under routine herd management in Northwest Spain. Anim. Reprod. Sci. 125:13-19.

Renaud, D. L., T. Duffield, S. LeBlanc, D. Haley, and D. Kelton. 2017. Management practices for male calves on Canadian dairy farms. J. Dairy Sci. 100:6862-6871.

USDA-APHIS. 2017. National Animal Health Monitoring System (NAHMS). Accessed Dec. 22, 2017. https://www.aphis.usda.gov/ aphis/ourfocus/animalhealth/monitoring-and-surveillance/nahms. 